\title{
A PROTEÇÃO DO MEIO AMBIENTE NO SÉCULO XXI FRENTE AOS DESAFIOS E OPORTUNIDADES DAS NOVAS TECNOLOGIAS INFORMACIONAIS ${ }^{1}$
}

Letícia Bodanese Rodegheri $^{2}$ Rafael Santos de Oliveira ${ }^{3}$

Resumo: O ativismo digital é entendido como um movimento que se utiliza da Internet e dos benefícios dela decorrentes para engajar a população a livremente expressar as ideias, opiniões e críticas e, também, a fomentar a execução de projetos destinados à proteção do meio ambiente. $\mathrm{O}$ artigo, utilizando-se dos métodos bibliográfico e documental, objetiva, ao cotejar dados obtidos pelo Comitê Gestor da Internet no Brasil, verificar a viabilidade e o êxito da execução de projetos que visam à ampliação da proteção jurídica do meio ambiente, denunciando-se abusos e irregularidades através da Internet. Conclui-se que, mesmo sendo restrito o acesso à rede no Brasil, os movimentos online criados para a defesa do meio ambiente repercutem nas mais variadas esferas da sociedade e influenciam diretamente a população e os governantes.

Palavras-chave: Ativismo digital; Novas mídias; Meio ambiente; Ativismo ambiental.

\section{INTRODUÇÃO}

A destacada atuação do movimento ambientalista no século XXI não somente mobiliza multidões na conscientização para a preservação do meio ambiente, como também alerta para a existência e frequente ocorrência de acidentes ambientais, desmatamentos, efeitos decorrentes do aquecimento global, entre outros. Surge, neste patamar, um questinamento central: por que não fazer uso da Internet, ferramenta rápida que interliga multidões no mesmo espaço de tempo, independentemente das barreiras territoriais, para a propagação de tais movimentos?

A crescente utilização das Novas Tecnologias da Informação e Comunicação (NTICS), em especial da Internet, para a defesa dos movimentos ambientais, é um fator que desponta, na atualidade, com grande força de atuação. A população vem, de forma crescente, utilizando-se da Internet para o engajamento na construção de movimentos atuantes diretamente nas carências e expectativas dos cidadãos.

\footnotetext{
${ }^{1} \mathrm{O}$ presente artigo representa os resultados parciais do Projeto de Pesquisa: "Ativismo digital e as novas mídias: desafios e oportunidades da cidadania global", desenvolvido no Curso de Direito da Universidade Federal de Santa Maria (UFSM).

${ }^{2}$ Acadêmica do $9^{\circ}$ semestre do Curso de Direito da Universidade Federal de Santa Maria. Integrante dos Projetos de Pesquisa "Ativismo Digital e as novas mídias: desafios e oportunidades da cidadania global" e "(Des)controle da blogosfera: entre a regulação e a censura no ciberespaço". Pesquisadora bolsista do Programa FIPE Júnior/UFSM. E-mail para contato: leticiabrodegheri@gmail.com.

3 Doutor em Direito pela Universidade Federal de Santa Catarina (UFSC). Professor Adjunto I no Departamento de Direito da Universidade Federal de Santa Maria (UFSM). E-mail: advrso@gmail.com.
} 
III SEMINÁRII ECDLOGIA

POLÍTICA

Trata-se do chamado "ativismo ambiental" que, conjugando as facilidades decorrentes do uso da Internet e o próprio ativismo inerente aos projetos de defesa do meio ambiente, objetivam conferir maior publicidade e dinamicidade aos desastres e também aos movimentos que atuam precipuamente para a proteção meio ambiente. Assim, iniciativas online são criadas e disseminadas para que a grande comunidade virtual possa contribuir na preservação e no combate a tais práticas.

O artigo objetiva verificar a viabilidade e o êxito destes mecanismos online cuja finalidade é tutelar o meio ambiente, a exemplo das organizações não governamentais Greenpeace e $W W F$, bem como de manifestações esboçadas nas redes sociais. A Internet surge, neste sentido, como o meio de comunicação e de difusão da informação hábil a permitir que qualquer cidadão, com acesso à rede possa manifestar suas opiniões, críticas e, assim, também participar da construção destas mobilizações.

No entanto, sabe-se que, nos dias de hoje, mesmo com estas facilidades na troca de dados, o acesso e a participação em tais movimentos ainda é restrito, em virtude não somente do grande poder de influência e de seleção de conteúdo realizado pela mídia tradicional, como também pelo desafio que se coloca à frente do Brasil de universalizar o acesso à Internet.

Para desenvolver o artigo empregaram-se os métodos bibliográfico e documental e dividiu-se o mesmo em três tópicos centrais, a saber: na primeira parte será analisada a construção do ativismo digital, destacando-se as características marcantes do movimento. Na segunda parte serão abordados os dados obtidos junto ao Comitê Gestor da Internet no Brasil (CGI), demonstrando-se os desafios que se colocam à frente do Brasil para a ampliação do acesso à rede. No último tópico será analisado o chamado "ativismo ambiental", trazendo-se casos práticos que demonstram a largar utilização da rede na defesa e promoção do meio ambiente.

\section{DO ATIVISMO DIGITAL À PARTICIPAÇÃo POLÍTICA NO SÉCULO XXI}

A sociedade moderna adotou, quase de forma generalizada, as NTICs, em especial a Internet, como um espaço aberto e propício ao fomento de debates relativos a temáticas outrora discutidas apenas de forma presencial. Maria Eduarda Gonçalves (2003, p. 07) traz que a penetração da Internet é uma das características marcantes da sociedade contemporânea, seja na vida econômica, social e política: "Para além de seus 
impactes na economia, estas tecnologias vêm afetando profundamente os modos de organização das relações sociais e as condições da realização de valores básicos das sociedades modernas, como a liberdade e a democracia".

Utilizada, primeiramente pelos Estados Unidos, com finalidade bélica, a Internet passou, de mero meio de transmissão de informações a condição de local de encontro, debate e engajamento da defesa de movimentos sociais e políticos. Chegou a referido status devido, em grande parte, às facilidades oferecidas, dentre as quais se destacam a velocidade na transmissão de dados, o baixo custo e a facilidade de uso.

Os cibernautas organizam-se em um ambiente, como por exemplo, em um blog, site ou rede social, com o intuito de propagar as ideias na forma de uma militância ativa e atuante na web. Trata-se de uma forma de ação política organizada que utiliza a Internet como veículo de propagação de ideologias ou informações, buscando a transformação da realidade.

Ao publicar conteúdo na web, o cibernauta não somente opta pelo assunto de seu interesse e emite uma opinião ou crítica, como também engaja e movimenta outros cidadãos na defesa de interesses e escolhas que, muitas vezes, apresentam reflexos fora da Internet. Ao adquirir a condição de emissor de informação, sem a necessidade de prévio controle, o cidadão assume nítida postura ativista, na medida em que faz uso da Internet como um veículo de propagação de informações e ideias, com o escopo de transformar a própria realidade social.

Surge, assim, o ativismo digital ou ciberativismo, como mecanismo de ação política no ambiente virtual, sendo definido por Manuel Castells (2003, p. 115) como movimentos sociais que se configuram em:

[...] aç̃oes coletivas deliberadas que visam a transformação de valores e
instituições da sociedade, [que] manifestam-se na e pela Internet. O mesmo
pode ser dito do movimento ambiental, o movimento das mulheres, vários
movimentos pelos direitos humanos, movimentos de identidade étnica,
movimentos religiosos, movimentos nacionalistas e dos
defensores/proponentes de uma lista infindável de projetos culturais e causas
políticas. O ciberespaço tornou-se uma ágora eletrônica global em que a
diversidade da divergência humana explode numa cacofonia de sotaques.

Maria Eugênia Rigitano (2012, p. 03) trata o ativismo digital como um mecanismo de ação democrática no ambiente virtual, pois há a possibilidade de difundir informações e reivindicações sem mediação: “[...] com o objetivo de buscar apoio e 
III SEMINÁRII ECDLOGIA

POLÍTICA

E DIREITO NA AMÉRICA LATINA

opções, matérias e argumentos sejam conhecidos e debatidos por uma infinidade de cidadãos. Entretanto, uma variedade de desafios coloca-se à frente do Brasil para que tais facilidades sejam estendidas a toda população, porquanto o acesso à Internet no país ainda é deficitário, conforme será abaixo analisado.

\section{DESAFIOS TECNOLÓGICOS À AMPLIAÇÃo DO ACESSO À REDE NO BRASIL}

A Internet é um mecanismo que propicia a rápida difusão de acontecimentos e fatos, porque um acidente como um vazamento de petróleio, por exemplo, mesmo que ocorrido do outro lado do oceano já não passa despercebido. Há diversos emissores que enviam textos, fotos, vídeos e mensagens como forma de denunciar abusos, violações de direitos humanos, catástrofes, massacres, ou simplesmente transmitir informação sobre determinado acontecimento.

A Internet proporciona a ampliação do espaço de ação dos movimentos sociais que estão organizados no ambiente tradicional, porque passa a difundir informações e a veicular denúncias com o intuito de mobilizar uma quantidade razoável de pessoas em torno de uma causa específica ou de um tema. $\mathrm{O}$ ambiente virtual passa a ser visto como um canal de comunicação complementar em que os objetivos se unem em torno de um ideal, mobilizando internautas e criando espaço para discussões e protestos dentro e fora da rede mundial de computadores.

Entretanto, o Brasil ainda vive uma contradição em termos de acesso à Internet, uma vez que, constatados avanços anuais no número de usuários, ainda subsistem muitos excluídos digitalmente que, na maioria dos casos, são oriundos de classes baixas e de pouca escolaridade, os quais não necessitam apenas do acesso à rede, como também a qualificação necessária para que o mesmo possa ser efetuado.

O Comitê Gestor da Internet no Brasil ${ }^{4}$ (CGI.br), em pesquisa realizada no ano de 2010, utilizando-se da definição de usuário da Internet como aquele indivíduo que

\footnotetext{
4 A pesquisa foi realizada com base nas orientações da Organização para a Cooperação do Desenvolvimento Econômico (OCDE) e do Observatório para a Sociedade da Informação na América Latina e Caribe (OSILAC). Para tanto, foi desenhada uma amostra principal com 23.107 domicílios, cuja coleta de dados ocorreu entre os meses de agosto e outubro de 2010, em todo o território nacional, inclusive nas áreas rurais. Posteriormente, a fim de consolidar os resultados obtidos em determinados
} 
III SEMINÁRII ECOLOGIA

PDLÍTICA

E DIREITO NA AMÉRICA LATINA

fez uso destas tecnologias nos últimos três meses, identificou o acesso e uso da Internet no Brasil, conforme demonstrado no quadro abaixo.

Quadro 1 - Estatísticas do acesso e uso da Internet no Brasil

\begin{tabular}{|c|c|c|c|c|}
\hline & $2005(\%)$ & $2008(\%)$ & $2009(\%)$ & $2010(\%)$ \\
\hline $\begin{array}{l}\text { Domicílios com computadores na área } \\
\text { urbana }\end{array}$ & 17 & - & - & 39 \\
\hline Conexão de Internet na área urbana & 13 & - & - & 31 \\
\hline Excluídos digitalmente & - & 62 & - & 56 \\
\hline Não usuários - área rural & - & 82 & & 80 \\
\hline Não usuários - área urbana & - & 59 & - & 51 \\
\hline
\end{tabular}

Fonte: elaborado a partir de informações contidas em CGI.br, 2011.

O grupo mais numeroso que não usa a Internet está na área rural (84\%). O mesmo ocorre entre os brasileiros que residem nas regiões Nordeste e Norte, onde a proporção de não usuários corresponde a $72 \%$ e $66 \%$, respectivamente. E, ainda, $87 \%$ dos indivíduos da classe DE não utilizam a Internet. Ressalta-se que, na classe A, essa proporção é de apenas 16\%; e, por fim, 95\% dos brasileiros com mais de 60 anos de idade não são usuários, ou seja, não fizeram uso da rede nos últimos três meses (CGI, 2012).

As tecnologias como televisão e rádio estão praticamente universalizadas, enquanto que o computador e a conexão à Internet ainda possuem baixa penetração nos lares brasileiros, o que se justifica pelos seguintes entraves:

Quadro 2 - Razões da ausência de computador e/ou Internet nos lares brasileiros

\begin{tabular}{|l|c|c|c|c|}
\hline & $\begin{array}{c}\text { Alto } \\
\text { Custo } \\
(\%)\end{array}$ & $\begin{array}{c}\text { Falta de } \\
\text { disponibilidade de área } \\
(\%)\end{array}$ & $\begin{array}{c}\text { Falta de } \\
\text { interesse (\%) }\end{array}$ & $\begin{array}{c}\text { Falta de } \\
\text { habilidade (\%) }\end{array}$ \\
\hline $\begin{array}{l}\text { Domicílios sem } \\
\text { computador }\end{array}$ & 74 & - & 38 & 26 \\
\hline $\begin{array}{l}\text { Domicílios com } \\
\text { computador e sem acesso à } \\
\text { Internet }\end{array}$ & 49 & 23 & 16 & 12 \\
\hline
\end{tabular}

Fonte: elaborado a partir de informações contidas em CGI.br, 2011.

O alto custo ainda é uma das principais barreiras tanto para a aquisição de computadores, como para o acesso à rede, o qual é seguido pela falta de interesse e de

estratos, foi realizada uma amostra suplementar igual a 2.043 domicílios urbanos, cuja coleta ocorreu em fevereiro de 2011 (CGI, 2012). 
habilidade, respectivamente 5 . Estes dados indicam que, além de questões estruturais, as quais remetem ao custo dos equipamentos, a ampliação da posse de computador não depende apenas do acesso às TICs propriamente dito, mas também do desenvolvimento de habilidades, a partir de uma maior alfabetização digital da população, definida como a "aquisição de habilidades básicas para o uso de computadores e da Internet [...] em favor dos interesses e necessidades individuais e comunitários, com responsabilidade e senso de cidadania" (TAKAHASHI, 2000. p. 31).

Com relação à Internet, nesta edição da pesquisa, nota-se a queda do acesso discado (13\% dos domicílios da zona urbana) e um aumento das conexões de banda larga fixa (68\% dos domicílios). Quanto às conexões com barda larga móvel (a exemplo do 3G) cresceram 67\% em relação a 2009, nas áreas urbanas e 63\% nas áreas rurais. Já em relação à expansão das conexões com banda larga fixa, as classes que apresentaram os maiores índices de crescimento foram: DE, com 44\% em relação ao ano de 2009, C (5\%), B (1\%) e, na classe A, a penetração da banda larga fixa se manteve estável (CGI, 2012).

Diante de tais resultados, mesmo que a Internet ainda não se encontre difundida a toda a população brasileira, não se pode desconsiderar que a desnecessidade de autorização para expressar-se e a facilidade das trocas realizadas fomentam discussões, ampliam a motivação para participar e aumentam a gama e a diversidade de cooperação. O simples fato de existir um espaço aberto a todos, ainda que virtual, torna-se incentivador, resultando em um interesse maior na defesa do meio ambiente, conforme será a seguir tratado, com a demonstração de casos práticos.

\section{A UTILIZAÇÃo de FERRAMENTAS ONLINE PARA A PROTEÇÃo AO MEIO AMBIENTE}

Não é de hoje que os ambientalistas utilizam noticiários de televisão, rádios e jornais locais, regionais e nacionais para manifestarem-se sobre assuntos relacionados à preservação do meio ambiente, reciclagem do lixo, entre outros, com o objetivo de sensibilizarem e conscientizarem a população. O ambientalismo ou "movimento verde"

\footnotetext{
${ }^{5}$ Como forma de diminuir a problemática relativa ao acesso à Internet no Brasil, cita-se o Programa Banda Larga nas Escolas (PBLE), lançado no dia 04 de abril de 2008 pelo Governo Federal, pelo Decreto $\mathrm{n}^{\circ} 6.424$ que altera o Plano Geral de Metas para a Universalização do Serviço Telefônico Fixo Comutado Prestado no Regime Público - PGMU (Decreto $n^{\circ} 4.769$ ) e tem como objetivo conectar todas as escolas públicas urbanas à Internet, por meio de tecnologias que propiciem qualidade, velocidade e serviços para incrementar o ensino público no País (PROGRAMA, 2012).
} 
tem como principais objetivos a defesa do meio ambiente e as medidas a serem tomadas para a sua proteção. Tais movimentos, considerados sociais, são constituídos, principalmente, por organizações não governamentais e voluntários interessados em promover e incentivar a proteção do meio ambiente.

Mesmo antes do advento da Internet - e dos desafios que se colocam à frente de alguns países, como o Brasil, para ampliar e disseminar o acesso à rede -, o movimento é considerado como ativista, porque apresenta atuação independente, ou seja, não é vinculado a orientações políticas e nem objetiva a promoção pessoal de seus integrantes, mas tem como principal característica a defesa do meio ambiente.

Manuel Castells (1999-b, p. 161-162) trata do movimento ambientalista como "[...] uma atitude de vigilância capaz de restaurar a confiança e dar novo ânimo a valores éticos em tempos de cinismo generalizado". Afirma que as questões levantadas pelo movimento, interligadas com valores humanitários, chamam a atenção das pessoas e autoridades não somente pela seriedade do assunto, como também por imagens que “dizem mais do que mil palavras".

Ainda, traz exemplos em que a Internet contribuiu para a propagação da causa ambientalista, porque " [...] grupos locais em todo o mundo passaram a ter condições de agir de forma global, exatamente no mesmo nível em que surgem os principais problemas relativos ao meio ambiente" (CASTELLS, 1999-b, p. 162).

Grupos de interesses comuns passam a interagir conjuntamente, criando um ambiente de discussão que une pessoas de diferentes lugares e regiões, facilitando-se a prática do chamado "ativismo ambiental", como por exemplo, a Escola de Ativismo, criada em abril de 2011, é intitulada como a "primeira escola online de ativismo ambiental que se tem notícia" (ESTADÃO, 2012). Apresenta os seguintes objetivos: ampliar os instrumentos e estratégias de ação política e mobilização; aumentar o poder de influência política de organizações e movimentos, indivíduais ou coletivos; e potencializar o ativismo no Brasil (ESCOLA, 2012).

O movimento surge sob a justificativa de que é necessário o emprego de estratégias e métodos mais organizados e adequados para garantir, proteger e promover os direitos humanos, a democracia e a sustentabilidade. Dentre as ações do grupo, destaca-se o curso "Ativismo e Mobilização para a Sustentabilidade (AMS)" que possui duração de nove semanas, sendo oito de forma online e uma presencial. De acordo com 
o programa, discutem-se questões ambientais, econômicas e sociológicas, bem como a ação coletiva e não violência, abordagem sobre o ativismo no Brasil, etc., de modo a fomentar e incentivar a realização de mais mobilizações em prol do meio ambiente.

Também, com expressivo destaque, encontram-se as manifestações esboçadas pelos próprios cibernautas, nas redes sociais, e que objetivaram fazer um apelo à Presidenta Dilma Roussef para que o projeto do novo Código Florestal fosse vetado. Lançou-se a Campanha "Veta Dilma" e, depois de aprovado o projeto no Congresso Nacional, intensificou-se para "Veta tudo, Dilma!" (UOL, 2012). O movimento, que teve grande adesão no Twitter e Facebook ${ }^{6}$, foi também estampado em placas levantadas por artistas e modelos e, ainda, em tirinhas do Maurício de Souza, demonstrando que a força de tais mobilizações e, consequentemente, da Internet como veículo de propagação e difusão dos mesmos.

Mesmo que tais manifestações não alcancem o completo êxito e sucesso esperado, esta postura dos cibernautas enfraquece os defensores das teorias que o uso das novas tecnologias da informação não mudaria a participação político-democrática através da rede virtual, porque o processo de mobilização passa pelas mídias tradicionais, que ainda estão sob o domínio de poucos.

Tais mecanismos, em um primeiro momento, apenas oferecem um local de encontro, ou seja, de conexão entre os internautas e de difusão de informações. Entretanto, com o passar do tempo e com a crescente utilização, facilita-se não somente a comunicação, como também a criação e o engajamento na proteção a outros assuntos, diretamente ligados ao cotidiano das pessoas: "[...] essas redes proporcionaram mais voz às pessoas, mais construção de valores e maior potencial de espalhar informações. São, assim, essas teias de conexões que espalham informações, dão voz às pessoas, constroem valores diferentes e dão acesso a esse tipo de valor" (RECUERO, 2009, p. 25).

Com o escopo de reafirmar a força de tais mobilizações, destaca-se o Greenpeace como um exemplo de mobilidade de online, pois possui site, blog, Facebook, Twitter, Youtube e Flickr. De acordo com a própria descrição no site,

\footnotetext{
6 "A principal página sobre o assunto no Facebook possui mais de 12 mil pessoas "curtindo" - quase o dobro dos usuários que "curtem" a página contrária à construção da usina Belo Monte -, a foto da modelo Gisele Bündchen com a frase: "Veta tudo, Dilma!" foi compartilhada na mesma rede social por quase 2 mil pessoas e o vídeo em que a atriz Camila Pitanga pede diretamente para a presidenta vetar o projeto foi visto por 20,5 mil usuários do YouTube" (ÚLTIMO SEGUNDO, 2012).
} 
encontra-se uma das principais características da organização, qual seja, o chamado "confronto pacífico", porque a entidade procurar trabalhar utilizando "[...] confrontos não violentos e criativos para chamar a atenção do público para determinado problema ambiental, mostrando que essa postura é alternativa eficaz de comportamento" (GREENPEACE, 2012).

Outra organização que denota expressiva preocupação com o meio ambiente e também em engajar um maior número de pessoas interessadas na defesa da causa é a Rede WWF que, além de contar com participação em sites, blogs, redes sociais e demais aplicativos, apresenta o mecanismo "Afilie-se", alertando que o Brasil possui uma das biodiversidades mais ricas do mundo, mas que está ameaçada e, “[...] por isso, a natureza precisa da sua ajuda. [...] Sua colaboração é fundamental para conservarmos o meio ambiente e garantirmos qualidade de vida para nós e nossas futuras gerações" (WWF, 2012). Ao clicar no aplicativo, abre-se um espaço para o preenchimento e dados pessoais e, também, a escolha da modalidade de doação monetária para a instituição. Além da arrecadação em dinheiro, a organização procura interagir com os cibernautas através do aplicativo "Ajude a divulgar", consistente em propagar a instituição e sua atuação nos mais variados meios de comunicação, seja televisão, jornal ou a Internet. Para tanto, disponibiliza banners para serem colocados em sites e blogs ou, ainda, para serem enviados por e-mail (WWF, 2012).

Embora os debates no ciberespaço ainda estejam restritos a uma parcela minoritária da população que detém acesso à Internet e que possui habilidade para utilizar todas as potencialidades dessas ferramentas, não há como negar que o ambiente virtual possibilita o aumento da interação entre os cidadãos e a discussão de projetos e iniciativas de proteção ao meio ambiente.

\section{CONSIDERAÇÕES FINAIS}

O movimento ambientalista é notoriamente conhecido pela força de atuação e capacidade de engajar multidões na defesa e proteção do meio ambiente. Com o advento da Internet, o movimento não poderia deixar de utilizar das facilidades decorrentes do meio para a propagação de notícias, veiculação de denúncias e engajamento da população na preservação do meio ambiente, espaço vital para o desenvolvimento da vida humana.

Encontram-se, na web inúmeros sites, blogs e os mais variados movimentos nas 


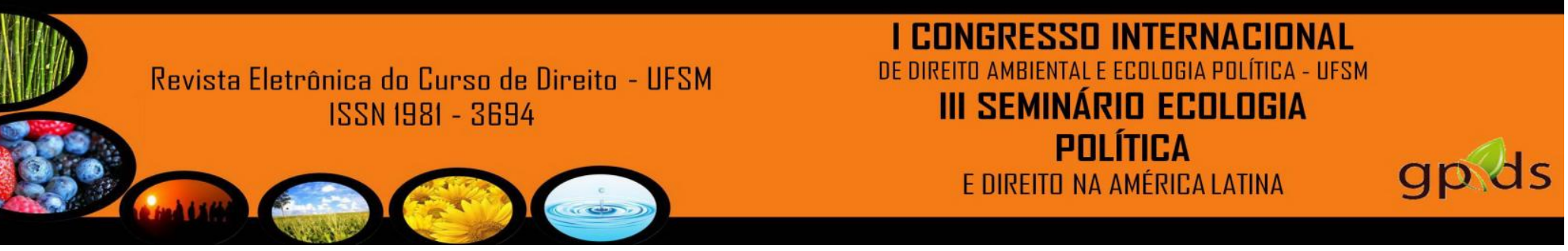

redes sociais que objetivam tratar de temáticas atuais e diretamente relacionadas com as deficiências do meio ambiente. O "Veta Dilma" e a dedicação e trabalho das organizações não governamentais mundialmente conhecidas, como a WWF e Greenpeace denotam que, mesmo que a população brasileira apresente restrito acesso à Internet, as medidas que vem sendo tomadas, de forma online, para a defesa do meio ambiente, engajam e movimentam muitas pessoas interessadas na proteção da causa.

Os dados coligados junto ao Comitê Gestor da Internet no Brasil demonstram um panorama desafiador na realidade brasileira em que, enquanto uma parcela minoritária detém acesso à rede e a utiliza para os mais variados fins - inclusive para a defesa dos movimentos ambientalistas -, ainda subsistem muitos cidadãos excluídos digitalmente, que sequer têm conhecimento dos benefícios e da força que a Internet apresenta atualmente.

Entretanto, enquanto o acesso não é expandido a toda a população, não se pode desconsiderar que as simples atitudes da população conectada, como "curtir" a página do Facebook do movimento "Veta Dilma" ou auxiliar monetariamente as organizações não governamentais, têm o condão de informar e conscientar um significativo número de cidadãos.

Embora incipientes, tais movimentos fortalecem as ações no "mundo real", porquanto a exemplo do "Veta Dilma", consituiu-em em um movimento de importante ocorrência e destaque, porque pressionou a presidenta Dilma Roussef a analisar com maior atenção o projeto de lei e a vetar alguns pontos que eram considerados extremamente nocivos ao meio ambiente. Ainda, conseguiu levar o projeto de volta à discussão no Congresso Nacional e, trouxe à tona, a possibilidade de convencer outros parlamentares a sensibilizarem-se com a causa e a apoiarem o movimento.

O espaço oferecido pela Internet constitui-se em uma importante ferramenta de debate público, permitindo uma participação democrática, ainda que incipiente, mas não totalmente efetiva, uma vez que está restrita a uma pequena parcela da população que possui recursos financeiros para participar neste meio. Com isso, a participação democrática está ocorrendo com o impulso da Internet em pontos dispersos na rede e sobre temas localizados.

\section{REFERÊNCIAS BIBLIOGRÁFICAS}

CASTELLS, Manuel. A galáxia da internet: reflexões sobre a internet, os negócios e a sociedade. Rio de Janeiro: Jorge Zahar, 2003.

A sociedade em rede. A era da informação: economia, sociedade e cultura; v. 1. São Paulo: Paz e Terra, 1999-a.

A sociedade em rede. O poder da identidade; v. 2. São Paulo: Paz e 


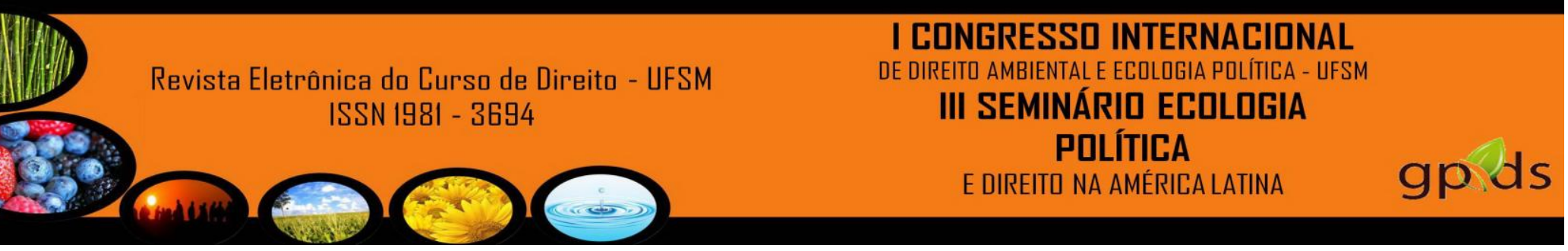

Terra, 1999-b

CGI.BR. Comitê Gestor da Internet no Brasil. Pesquisa sobre o uso das tecnologias de informação e comunicação no Brasil. Disponível em: <http://www.cgi.br/>. Acesso em: 30 ago. 2012.

ESCOLA DE ATIVISMO. Disponível em: <http://www.eativismo.org/>. Acesso em: 21 ago. 2012.

ESTADÃO.COM.BR. Ativismo ambiental ganha a web. Disponível em: $<$ http://www.estadao.com.br/noticias/vidae,ativismo-ambiental-ganha-aweb,750230,0.htm>. Acesso em: 20 ago. 2012.

GONÇALVES, Maria Eduarda. Direito da Informação: novos direitos e formas de regulaçao na sociedade da informação. Coimbra: Livraria Almedina, 2003.

GREENPEACE. Disponível em: <http://www.greenpeace.org/brasil/pt/>. Acesso em: 21 ago. 2012.

LEMOS, André; LÉVY, Pierre. O futuro da internet: em direção a uma ciberdemocracia planetária. São Paulo: Paulos, 2010.

PROGRAMA BANDA LARGA NAS ESCOLAS. Disponível em: $<$ http://portal.mec.gov.br/index.php?option=com_content\&view=article\&id=15808:pro grama-banda-larga-nas-escolas\&catid=193: seed-educacao-a-distancia $>$. Acesso em: 26 ago. 2012.

RECUERO, Raquel. Redes Sociais na Internet. Porto Alegre: Sulina, 2009.

RIGITANO, Maria Eugênia. Redes e ciberativismo: notas para uma análise do centro de mídia independente. Disponível em: <http://www.bocc.ubi.pt/pag/rigitano-eugeniaredes-e-ciberativismo.pdf>. Acesso em: 18 ago. 2012.

TAKAHASHI, T. (org.) Socinfo: Sociedade da Informação no Brasil: livro verde. Brasília: Ministério da Ciência e Tecnologia, 2000.

UOL NOTÍCIAS. Movimento "Veta Dilma!", sobre o Código Florestal, vira fenômeno nas redes sociais. Disponível em: $<$ http://noticias.uol.com.br/ciencia/ultimas-noticias/redacao/2012/05/04/movimentoveta-dilma-sobre-o-codigo-florestal-ganha-as-redes-sociais.htm>. Acesso em: 21 ago. 2012. 


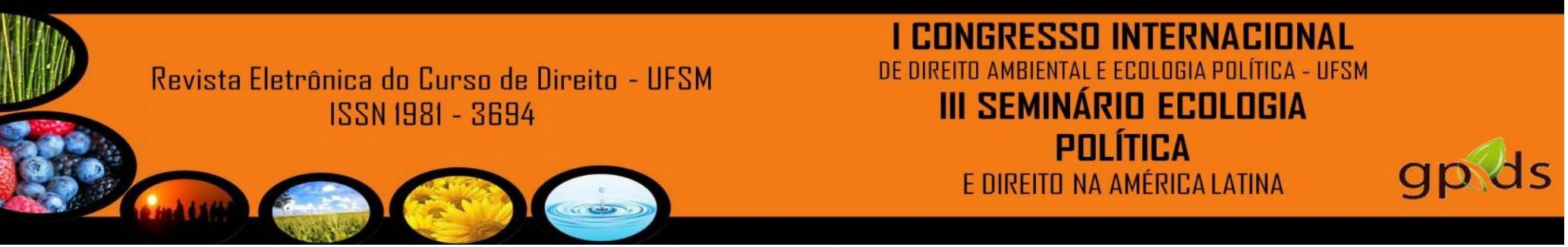

ÚlTIMO SEGUNDO. Para ambientalistas, vitória do Veta, Dilma independe de decisão sobre o Código. $<$ http://ultimosegundo.ig.com.br/politica/2012-05-25/para-ambientalistas-vitoria-doveta-dilma-independe-de-decisao-s.html>. Acesso em: 01 set. 2012.

WWF. Disponível em: <http://www.wwf.org.br/>. Acesso em: 20 ago. 2012. 